\title{
Hospital and Health System Policies Concerning the California End of Life Option Act
}

\author{
Cindy L. Cain, PhD, ${ }^{1}$ Barbara A. Koenig, PhD, ${ }^{2}$ Helene Starks, PhD, ${ }^{3}$ Judy Thomas, JD, ${ }^{4}$ \\ Lindsay Forbes, BA, ${ }^{2}$ Sara McCleskey, MS, ${ }^{5}$ and Neil S. Wenger, MD $^{6}$
}

\begin{abstract}
Background: The End of Life Option Act (EOLOA) legalized physician aid in dying for competent, terminally ill Californians in 2016. The law allows clinicians, hospitals, and health systems to decide whether to participate. About 4 in 10 California hospitals permit the EOLOA, but little is known about their approaches and concerns.

Objective: Describe hospital EOLOA policies and challenges.

Design and Measurements: Survey study of hospitals in California, administered September 2017 to March 2018. We describe hospital policies concerning the EOLOA and perform thematic analysis of open-ended questions about challenges, including availability of providers, process of implementing EOLOA, experiences of distress by providers and patients, and questions about medications.

Results: Of 315 hospitals surveyed, $270(86 \%)$ responded. Every surveyed hospital had established a position on the EOLOA. Among hospitals permitting EOLOA, 38\% required safeguards not required in the law, $87 \%$ provided for referral to another provider if the patient's physician did not participate, and $65 \%$ counseled staff, if needed. Among hospitals not permitting the EOLOA, nearly all allowed providers to follow patients choosing to pursue the EOLOA elsewhere and most permitted a provider to refer to another provider or system. Most hospitals expressed concerns about implementation of the EOLOA and interest in sharing promising practices. Conclusions: This survey of California hospitals demonstrates considerable heterogeneity in implementing the EOLOA. For many Californians, access to the EOLOA depends on where one receives medical care. Implementation would be improved by hospitals and health systems sharing promising practices.
\end{abstract}

Keywords: aid in dying; End of Life Option Act; health systems; hospital policy; law

\section{Introduction}

$\mathbf{T}$ He END of Life Option Act (EOLOA), which made physician aid-in-dying legally available to Californians in June, 2016, ${ }^{1}$ seeks to expand patients' choices at the end of life, while allowing providers and health care systems to opt out of participation. ${ }^{2,3}$ The EOLOA allows competent adult California residents with a terminal illness to voluntarily request a prescription for medications that will hasten death. The law includes steps to ensure that patients have a prognosis of six months or less, are able to self-administer the medications, and are making a well-considered decision that is not affected by undue internal or external influences. 4,5
Protections built into the law shield providers and health systems from being compelled to participate in acts they oppose. ${ }^{6,7}$ Health systems may declare that aid-in-dying does not fit within their mission and prohibit their employees from carrying out aid-in-dying while under their jurisdiction. Health system policies also can permit EOLOA and tailor implementation to reflect the organizational culture.

The EOLOA envisions the choice to use aid-in-dying as an intense decision-making process between a patient and his or her physician ${ }^{7}$ (as well as a consulting physician and possibly a mental health professional). However, practice arrangements are a key determining factor for physicians' ability to participate in this process, if they wish. California physicians

${ }^{1}$ Department of Sociology, University of Alabama at Birmingham, Birmingham, Alabama.

${ }^{2}$ Program in Bioethics, University of California San Francisco, San Francisco, California.

${ }^{3}$ Department of Bioethics and Humanities, University of Washington, Seattle, Washington.

${ }_{5}^{4}$ Coalition for Compassionate Care of California, Sacramento, California.

${ }^{5}$ Department of Health Policy and Management, University of California Los Angeles, Los Angeles, California.

${ }^{6}$ Division of General Medicine and Health Services Research, University of California Los Angeles, Los Angeles, California.

Accepted March 24, 2019. 
are increasingly in financial arrangements in which clinical practice may be guided by policies of a medical group or health system. In 2016, fewer than half of physicians held ownership in their practices. ${ }^{8}$ If health systems prohibit prescription of aid-in-dying medication, physicians who contract with these systems will be unable to participate in the EOLOA within the bounds of their contract, but may be able to participate, if desired, in other clinical settings. In turn, for many patients, access to aid-in-dying is influenced by the choices health care organizations make about implementing the law. ${ }^{9}$

In prior work, we reported on a survey of hospitals in California, many of which reflect the policies of their parent health systems, which found that $87 \%$ of hospitals had a formal policy on the EOLOA: $39 \%$ of these hospital policies permit physicians to prescribe aid-in-dying medications and $61 \%$ prohibit the EOLOA. ${ }^{10}$ Hospital and health system policies can have important implications for the patient's experience of the EOLOA, particularly in terms of provider referral practices and protocols that ensure compliance with the Act. In this article, we build on our previous findings by describing the content of hospital policies concerning the EOLOA and exploring promising practices and areas in need of additional attention.

\section{Methods}

We surveyed California hospitals between September 2017 and March 2018 (15-21 months after initiation of the EOLOA). The project was approved by the UCLA Institutional Review Board (16-000550). We used hospitals as an entry point for health systems for several reasons. First, the majority of hospitals in California are part of larger health systems, which may include other hospitals, outpatient and specialist care settings. ${ }^{11}$ The EOLOA is not designed to be carried out in hospitals, but hospitals are often central to larger health care networks; in some cases the hospital policy covers affiliated settings, and hospitals commonly develop policies to guide physicians practicing in the greater environment. Second, many health systems house their policy administration process in the hospital. Finally, even though patients are unlikely to self-administer EOLOA medications in the hospital setting, many patients with a terminal illness will be hospitalized as they near the end of their lives. Previous research has shown that these hospitalizations are critical moments in end-of-life decision making, ${ }^{12,13}$ so this is a time when patients consider options such as the EOLOA.

\section{Hospital sample}

We attempted to survey each hospital in California to which the EOLOA might apply and took into account whether hospitals were part of multihospital $(\geq 3)$ health systems. We constructed the population of hospitals using 2016 data from the Office of Statewide Health Planning and Development (OSHPD) ${ }^{14}$ and excluded children's hospitals, rehabilitation settings, long-term acute care settings, psychiatric care settings, and hospitals that were closed or suspended. OSHPD excludes Veteran's hospitals, which by federal law are not permitted to participate in the EOLOA.

We counted each hospital as a separate health care setting. If a health system set policy for all hospitals in the system, we applied the response to all affiliated hospitals. If the hospital set its own policy, we applied the response to only that setting. In both cases, we asked whether the hospital policy covered outpatient facilities affiliated with the hospital. We estimated that of the 315 hospitals in our population, up to 135 unique policies could exist (because of clustering of hospitals within systems); we completed surveys characterizing 89 of these policies (66\%). Fifty-three of these (covering 229 hospitals) applied to all inpatient and outpatient facilities associated with the hospital or health system. For example, a large integrated health system may include several hospitals and outpatient clinics, and a single policy governed all of these settings. In contrast, 36 hospital policies (covering 41 hospitals) applied only to physicians practicing in their inpatient settings; those policies did not offer guidance for the outpatient locations where their patients also receive care.

\section{Survey construction and administration}

We constructed a survey using previously fielded items from surveys of hospice approaches to aid-in-dying laws ${ }^{15,16}$ and developed original items specific to hospital settings. The survey asked about the range of end-of-life services available for patients, EOLOA policy content, experiences with the EOLOA (if applicable and collected at the health system level), and EOLOA training and educational materials. In an open-ended fashion, the survey also asked explicitly about potential challenges that had been identified in previous studies ${ }^{5,17-20}$ : availability of willing providers, process of carrying out the EOLOA, and distress among providers and/or patients. We presented the survey domains to a statewide steering committee that included clinicians, administrators, patient advocates, and legal experts (www.eoloptionacttaskforce.org) and received advice to collect anonymous data to enhance response. We pretested the survey (including open-ended items) with a subsample of representatives from the steering committee. The survey was administered by telephone and required $\sim 20$ minutes. Just under a mean of five calls was required to reach the person identified as most knowledgeable about the organization's EOLOA policy. Respondents were from a variety of organizational roles, including administration $(24 \%)$, social work or case management $(44 \%)$, palliative care $(21 \%)$, and physician leadership (11\%).

\section{Analysis}

We used descriptive statistics to characterize the hospital sample, differences between responding and nonresponding hospitals, and the content of hospital and health system policies concerning EOLOA implementation. Every surveyed hospital described whether aid-in-dying was permitted, even if the hospital did not have a written policy in place. Of the $106(39 \%)$ hospitals that permit physicians to write prescriptions under the EOLOA, 97 had a formal policy regarding the EOLOA and 9 did not. Of the 164 (61\%) hospitals that forbid physicians from writing prescriptions under the EOLOA, 138 hospitals had a formal written policy. We also used OSHPD data to characterize the hospitals' overall patient volumes and capture a sense of the proportion of patients receiving care in participating and nonparticipating systems as an estimate of the impact on overall access across California. We used Stata 15 for analyses. ${ }^{21}$ 
We analyzed open-ended survey questions about challenges or concerns using a qualitative thematic approach. ${ }^{22}$ We counted how many hospitals reported each issue as a challenge and then used content analysis to analyze responses inductively. The survey personnel were all trained to record verbatim responses to open-ended questions about challenges. Within each of the four implementation challenges, we identified subthemes, which we summarize below and include verbatim comments from respondents. Two authors (C.C., N.W.) reviewed the qualitative responses and discussed discrepancies. Through this process, we found that challenges with medications were widely discussed and common across all prompts; we present medication issues separate from the original domains.

\section{Results}

Of 315 California hospitals within the scope of the study, survey responses were received for 270 (86\%). Twelve hospitals declined participation explicitly and 33 were unreachable. The responding 270 hospitals were covered by 89 unique policies. Nonresponding hospitals were more likely to be rural and less likely to be part of a hospital system or to have nonprofit status (Table 1).

Of responding hospitals, $68 \%$ had nonprofit status, $27 \%$ were religiously affiliated, and $8 \%$ contained 500 or more beds. Seventy-one percent $(n=191)$ of these hospitals belonged to a system that included three hospitals or more. Responding hospitals were responsible for $90 \%$ of the California 2016 discharges from the 315 hospitals in our sampling frame (Table 1). Most hospitals reported that they provided palliative care $(84 \%)$, spiritual support for patients $(96 \%)$, and bereavement support for families $(76 \%)$.

\section{Content of hospital policies regarding the EOLOA}

There was considerable variation in the content of policies, both among hospitals that permitted the EOLOA and those that did not. We present information reported by hospitals

Table 1. Characteristics of Hospitals That Completed Surveys AND NonResponders $(N=315)$

\begin{tabular}{lcc}
\hline & $\begin{array}{c}\text { Completed surveys } \\
(\mathrm{n}=270), \mathrm{n}(\%)\end{array}$ & $\begin{array}{c}\text { Nonresponders } \\
(\mathrm{n}=45), \mathrm{n}(\%)\end{array}$ \\
\hline $\begin{array}{l}\text { Religiously affiliated } \\
\text { Teaching hospital }\end{array}$ & $28(27)$ & $8(18)$ \\
$\begin{array}{l}\text { Rural hospital } \\
\text { Member of hospital } \\
\quad \text { system }\end{array}$ & $39(14)^{*}$ & $4(9)$ \\
$\begin{array}{l}\text { Large hospital } \\
\quad \text { 500+ beds) }\end{array}$ & $191(71)^{*}$ & $17(38)^{*}$ \\
$\begin{array}{l}\text { Nonprofit status } \\
\text { Percentage of } \\
\text { discharges }\end{array}$ & $22(8)$ & $6(13)$ \\
\hline
\end{tabular}

Note: Percentages represent column percentages. Chi-square tests used to determine statistically significant differences between groups.

$* p \leq 0.001$

${ }^{a}$ Hospital system defined as three or more hospitals.

${ }^{\mathrm{b}}$ Percentage of 2016 California discharges, out of a total of 3,100,970 discharges from 315 hospitals within the scope of this study. that had formal policies as well as those without written policies that had set forth guidelines for application of the EOLOA.

Participating hospitals ( $n=106$ with 35 policies). Across the hospitals that permit physicians to prescribe aidin-dying medications, the vast majority do not allow patients to self-administer the medications in the inpatient setting. Eight of these hospitals prohibit physicians from being present at the time of a patient's self-administration of the aid-in-dying medications. The majority $(87 \%)$ of these hospitals provide for referral to another provider if the patient's attending physician did not participate. Approximately, 65\% provided counseling for staff in cases where the EOLOA brought up issues of concern. Just under $40 \%$ of hospitals required additional safeguards that the law did not explicitly define; these include palliative care consultation; mental health consultation; social work involvement; or administrative, risk management, or ethics review. About one third of hospitals collected data (beyond that required by law) on patients who requested the EOLOA (Table 2). About 1.5 years after implementation, 74\% of the health systems reported receiving at least one request for the EOLOA and $49 \%$ reported providing at least one prescription for aid-in-dying medication.

Table 2. Content of Hospital Policies for Hospitals That Permit the END-OF-Life Option $(N=106$ Hospitals and 35 Policies)

\begin{tabular}{lccc}
\hline & $\begin{array}{c}\text { Hospitals, } \\
\mathrm{n}(\%)\end{array}$ & $\begin{array}{c}\text { Policies, } \\
\mathrm{n}(\%)\end{array}$ & Discharge, ${ }^{\mathrm{a}} \%$ \\
\hline Self-administration in facility & & \\
Permitted & $7(7)$ & $4(11)$ & 3 \\
Not permitted & $94(89)$ & $27(77)$ & 36 \\
Not addressed & $5(5)$ & $4(11)$ & 2 \\
Physician presence at ingestion & & \\
Permitted & $48(45)$ & $11(31)$ & 21 \\
Not permitted & $8(8)$ & $5(14)$ & 5 \\
Not addressed & $50(47)$ & $19(55)$ & 16 \\
Helps patients find alternate physician if attending opts out \\
Yes & $92(87)$ & $26(74)$ & 36 \\
No & $3(3)$ & $3(9)$ & 2 \\
Not addressed & $11(10)$ & $6(17)$ & 4 \\
Provides counseling for staff if & needed & \\
Yes & $69(65)$ & $23(66)$ & 30 \\
No & $37(35)$ & $12(34)$ & 12 \\
Requires additional safeguards & & \\
Yes & $40(38)$ & $14(40)$ & 13 \\
No & $66(62)$ & $21(60)$ & 29 \\
Collecting data on requests & & \\
Yes & $35(33)$ & $13(37)$ & 19 \\
No & $71(67)$ & $22(63)$ & 23 \\
\hline
\end{tabular}

Includes both formal and informal policies.

${ }^{\text {a}}$ Forty-two percent of hospital discharges, out of a total of $3,100,970$ discharges in California in 2016, were from hospitals that permit the EOLOA. The total percentage of discharges between Tables 2 and 3 does not add to $100 \%$ because $10 \%$ of hospital discharges from hospitals that did not respond to the survey. EOLOA, End of Life Option Act. 
Nonparticipating hospitals ( $n=164$ with 54 policies). Among hospitals not permitting the EOLOA, there was variation in the range of permitted responses to patients making a request. For example, $8 \%$ allow physicians to serve as the consulting physician for aid-in-dying requests while $27 \%$ of policies are silent on the subject. Referrals to another provider or system were permitted by $56 \%$ of these hospitals and not mentioned in $29 \%$ of the policies. Providers are allowed to give patients information about the EOLOA in $68 \%$ of hospitals; $22 \%$ did not address the issue. Thus, only $10 \%$ of such hospitals (representing $5 \%$ of hospital discharges) prevented information transmission about the EOLOA to patients. Nearly all of these hospitals allow providers to continue to provide care within their system (or the issue was not addressed in policy), even if the patient chooses simultaneously to pursue the EOLOA elsewhere (Table 3).

Table 3. Content of Hospital Policies for Hospitals That Do Not Permit the End-of-Life Option $(N=164$ Hospitals ANd 54 Policies)

\begin{tabular}{|c|c|c|c|}
\hline & $\begin{array}{l}\text { Hospitals, } \\
\mathrm{n}(\%)\end{array}$ & $\begin{array}{c}\text { Policies, } \\
\mathrm{n}(\%)\end{array}$ & Discharge, ${ }^{\mathrm{a}} \%$ \\
\hline \multicolumn{4}{|c|}{ Physician may act as consultant } \\
\hline Permitted & $13(8)$ & $8(15)$ & 4 \\
\hline Not permitted & $107(65)$ & $27(50)$ & 32 \\
\hline Not addressed & $44(27)$ & $19(35)$ & 13 \\
\hline \multicolumn{4}{|c|}{ Refer requesting patients out of system } \\
\hline Permitted & $92(56)$ & $28(52)$ & 27 \\
\hline Not permitted & $24(15)$ & 10 (19) & 7 \\
\hline Not addressed & $48(29)$ & $16(30)$ & 15 \\
\hline \multicolumn{4}{|c|}{ Physician may give information about EOLOA } \\
\hline Permitted & $112(68)$ & $33(61)$ & 35 \\
\hline Not permitted & $16(10)$ & $4(7)$ & 5 \\
\hline Not addressed & $36(22)$ & $17(32)$ & 9 \\
\hline \multicolumn{4}{|c|}{$\begin{array}{l}\text { Physician may continue to care for patient receiving } \\
\text { EOLOA elsewhere }\end{array}$} \\
\hline Permitted & $109(66)$ & $36(67)$ & 34 \\
\hline Not permitted & $3(2)$ & $2(4)$ & $<1$ \\
\hline Not addressed & $52(32)$ & $16(29)$ & 14 \\
\hline
\end{tabular}

Includes both formal and informal policies.

${ }^{a}$ Forty-eight percent of hospital discharges, out of a total of 3,100,970 discharges in California in 2016, were from hospitals that did not permit the EOLOA. The total percentage of discharges between Tables 2 and 3 does not add to $100 \%$ because $10 \%$ of hospital discharges from hospitals that did not respond to the survey.

\section{Challenges implementing the EOLOA and suggested solutions}

Among the 106 hospitals permitting participation in the EOLOA, 51\% reported that unavailability of providers was a challenge in implementation (see Table 4). Finding physicians willing to act as the attending was especially challenging in clinical areas most likely to get requests, such as oncology. ${ }^{23}$ Some reported difficulties finding other health professionals to assist in the process, especially pharmacy and hospice workers. Some hospitals tried to create a list of willing providers, but providers sometimes were reluctant to be named. One respondent reported: "The biggest challenge has been getting a confidential list of providers. I know there's one physician at our hospital who wanted to participate, but providers don't necessarily want to make that public because of how they might be treated." A few commented that provider unavailability has become less of a problem over time because comfort increased and operational processes were made clearer. Promising practices included setting up a peer network to help providers discuss concerns and structured debriefings for participating providers or for providers feeling conflicted about being unwilling to prescribe.

Twenty-seven percent of participating hospitals cited difficulties in carrying out the law. Respondents noted that the process is complex and the EOLOA leaves several operational questions unanswered; many health systems left these details to individual providers. Health systems sometimes felt isolated and wondered how to answer operational questions. Several respondents commented that it would be great "to learn more about how other health care organizations are handling this issue", and "...to have a meeting or conference with other organizations who have been through the whole process to learn how they've handled everything." Several systems responded to the complexity by creating a protocol, usually managed by social workers, that guided patients and providers through the process. Implementation was hindered by ambiguities in the law, including the definition of "attending physician" and status of the law when it was under legal challenge.

A third of respondents $(33 \%)$ noted that they had heard reports of provider distress. Some providers initially were concerned that they would be compelled to participate, others worried that the law required practice changes that were difficult for providers. A participant said, "The amount of time it takes to do the process and the fact that it is a complete change in how physicians practice makes some unwilling or hesitant." Distress came from the extra time required to complete EOLOA activities and disproportionate burden if only a few providers participate. Education about the law, Schwartz rounds, and other structured discussion mechanisms were used to try to address some sources of provider distress.

Distress for patients or family members was discussed by $56 \%$ of respondents. Complexity and duration of the process exceeded patient and family expectations: "Some patients believe that the process will be easy and become frustrated when they can't get the drugs immediately." Some of the distress was due to the slow and bureaucratic processes designed to facilitate adherence to the EOLOA legal requirements. Another source of distress was when patients were deemed ineligible. Cost was a concern for many; not just the cost of medication, but also out-of-pocket expense when patients needed to go outside the system to find providers.

Difficulty obtaining the aid-in-dying medication emerged as a common challenge. ${ }^{24}$ As the EOLOA went into effect, the cost of secobarbital soared to over \$3500, making it difficult to access. Several hospitals reported seeking compounding pharmacies to create mixtures, but pharmacies were not always available and there was uncertainty about the best regimen. Others expressed concerns about handling unused aid-in-dying medication and addressing patients whose clinical condition changed. One participant said, "There is a need for more education about pharmacy issues, including disposing of meds." 


\begin{tabular}{|c|c|c|}
\hline Challenges & & Possible solutions \\
\hline \multicolumn{3}{|l|}{ Providers unavailable } \\
\hline $\begin{array}{l}\text { Physicians } \\
\text { (attending, } \\
\text { consulting, and } \\
\text { specialist) }\end{array}$ & $\begin{array}{l}\text { Oncology is not excited to participate and } \\
\text { palliative care opted out. Need to identify } \\
\text { which hospices will participate. }\end{array}$ & $\begin{array}{l}\text { Nurtured referral pool. We provide support to } \\
\text { those providers and invest in education to } \\
\text { address nonparticipation concerns. } \\
\text { Have a system set up so that if the first provider is } \\
\text { not willing or able, local teams will set up. This } \\
\text { leaves room for people to opt out, but still } \\
\text { ensures access. Did a lot of upfront educational } \\
\text { work, peer group meetings, and now local team } \\
\text { meetings. }\end{array}$ \\
\hline $\begin{array}{l}\text { Other health } \\
\text { professionals }\end{array}$ & $\begin{array}{l}\text { Many willing participants in this area. The } \\
\text { problem is with finding pharmacies. }\end{array}$ & $\begin{array}{l}\text { Have created an information line. } \\
\text { Lessening with time. With more experience and } \\
\text { education, more providers are willing to } \\
\text { participate. }\end{array}$ \\
\hline
\end{tabular}

\section{Difficult process \\ Implementing a complex process \\ It is a real struggle to figure out how to implement this law in an acute care facility whose mission is to save lives, not end them. It is a difficult process. \\ We also need more support for documentation in the electronic medical record. \\ Providers think it is too much paperwork (e.g., fill out follow-up forms, even if patient does not take the meds).
Lack of clarity from legal perspective \\ Many operational aspects are not addressed in the law. The law is geared toward physicians, but most places take this on as an institution. \\ The language around the attending physician is not clear and there are challenges to getting appointments for all steps.}

Configure it as a process that should be clear to patient, family, and providers - even if never done it before. The goal is to shepherd them through the process, which the patient coordinator helps with quite a bit. The local team makes sure all understand the process and documentation. This can be a challenge if patient wants a quick decision or declines quickly. The situation can become more urgent, but we cannot make it happen any faster because of the conditions in the law.

\footnotetext{
Distressed providers Compelled to participate

Change in physician role and practice

Providers were distressed because they thought they would be compelled to participate.

The law requires that the patient make the request (not a surrogate), which differs from every other aspect of end-of-life care. Also, when the patient asks the doctor not to tell the family members about the request, this causes distress for the provider.

Recognition of being directly responsible for a patient's death.
}

Increased workload
Two people who will prescribe-they feel that it is unfair that they are the only ones.
Education, comfort on the part of the physician is critical.

Want to honor the decisions of providers to opt in or opt out, but also leave room for them to change their mind as they go. We take this on a case-by-case basis, so if there is moral distress, we do not want providers to feel cornered. There is always someone else who can help. Some hospice providers have felt like this is too much of a departure from their normal way of operating, so doing debriefs as needed.

Use Schwartz rounds to address issues for providers, from a range of backgrounds and positions.

\footnotetext{
Distressed patients or family members

Patients who do not qualify

When patients want to enroll and cannot (ALS esophageal tubes, because they cannot swallow), but they have capacity.

Duration of Cost the process

The process takes time and some patients are very far along in their illness.

Typically, money is the most distressing issue. Family issues - we had a case where extended family members were not included in decision making and were very upset. Also, how to pay for it when insurance does not cover it.
} 
TABle 4. (CONTINUED)

\begin{tabular}{|c|c|c|}
\hline Challenges & & Possible solutions \\
\hline \multicolumn{3}{|l|}{ Medications } \\
\hline Compounding & $\begin{array}{l}\text {...prescriptions are hard to get. Secobarbital is } \\
\text { hard to find and they do not work with a } \\
\text { compounding pharmacy. }\end{array}$ & $\begin{array}{l}\text { All requests go through our own pharmacy, which } \\
\text { is staffed with a pharmacist and a LCSW. } \\
\text { It can also be challenging to take the medications, } \\
\text { so we have a pharmacist come and out and } \\
\text { walk through all the directions and answer any } \\
\text { questions. }\end{array}$ \\
\hline $\begin{array}{l}\text { Aid-in-dying } \\
\text { medication } \\
\text { regimen }\end{array}$ & $\begin{array}{l}\text { Knowing the right cocktail is challenging, as is } \\
\text { the cost of medications. There may be } \\
\text { problems with unequal access given the costs. }\end{array}$ & \\
\hline Disposal if unused & $\begin{array}{l}\text { Some concerns about the meds if patient status } \\
\text { changes or they do not use the meds. }\end{array}$ & $\begin{array}{l}\text {... working with a system-wide taskforce to create } \\
\text { pharmacy guidelines. }\end{array}$ \\
\hline
\end{tabular}

Survey conducted at the hospital level 15-21 months after implementation of the EOLOA. Table includes direct quotes from respondents.

\section{Discussion}

About 18 months after initiation of the EOLOA, hospitals across California have taken positions regarding aid-indying. Our survey demonstrates considerable variability in hospitals' approach to this newly available aspect of care at the very end of life. While many hospital policies narrowly affect physician behavior in only the inpatient setting, the majority of policies we examined had implications for physicians' practice in settings outside the hospital and these have implications for their response to patients requesting aid-in-dying. Among the $39 \%$ of hospital policies permitting the EOLOA $(n=106), 38 \%(n=40)$ overlay additional safeguards and care processes on the already-complex set of procedures dictated by the Act. These processes, many of which aim to support physicians, may exacerbate patients' and family members' sense that the process takes too long or is too burdensome. Among the $61 \%$ of hospitals disallowing the EOLOA $(n=164)$, most permit sharing of information about aid-in-dying and allow patients electing to use the EOLOA to continue to be followed, yet $15 \%$ forbid referral outside the system to a willing provider. This survey shows that for a substantial number of California residents, where one receives medical care will dictate provider response and approach to a request for the EOLOA. As shown previously, hospitals that opt out of participation account for $48 \%$ of hospital discharges. ${ }^{10}$

This evaluation of hospital policies also shows that hospitals and their umbrella health systems carefully considered many of the issues important to patients and critics of the law. ${ }^{25,26}$ Previous studies of hospice policies similarly illustrate a high level of nuance in institutional responses. ${ }^{16}$ Over half of policies permitting aid-in-dying addressed whether physicians could be present for selfingestion of the aid-in-dying drug and the vast majority suggested a mechanism for patients to be referred to other providers if their attending physician was not participating. Furthermore, we reported previously that $93 \%$ of hospitals permitting the EOLOA produced training materials for physicians and half had instruction available for patients. ${ }^{10}$ Hospitals opting out of the EOLOA were less likely to have educational materials available for physicians (63\%) and patients $(15 \%) .^{10}$ Universal availability of educational materials might address some of the hospital and health system concerns, especially those focused on provider and patient/family distress.

Despite hospitals having policies, most had concerns about carrying out the EOLOA. Many hospitals reported difficulty finding participating providers, although some indicated partial resolution of this issue over time. Many felt that some of the steps in the legal process were unclear, leading to construction of additional components to facilitate compliance. Lack of experience and familiarity with the steps in the EOLOA led many to report provider and patient/family distress. Many hospitals and health systems desired advice on best practices and some facilities described innovative structures and approaches that might be shared. This survey strongly suggests that hospitals and health systems should share best practices through peer networks and that these should extend to hospices, pharmacies, and other provider groups.

This study of California EOLOA hospital policies has limitations. It is a study of hospitals and not physicians; we cannot describe the proportion of physicians or patients affected by each of the policies. But we were able to capture the wide diversity of situations that patients may encounter when making an EOLOA request. Future research should complement these findings by examining hospice, longterm care, acute rehabilitation facilities, oncology centers, and various provider groups. Better insight into what happens to patients in health systems that opted out of participation in the EOLOA is needed. Additionally, while our response rate is high $(86 \%)$, we are disproportionately missing hospitals in rural areas.

This survey of California hospitals demonstrates that hospitals and health systems are engaged in application of the EOLOA, but there is great heterogeneity in participation and need for sharing promising practices.

\section{Acknowledgments}

The authors acknowledge the California Health Care Foundation and the Stupski Foundation for supporting this work, as well as Thomas R. Weinberger for supporting efforts that led to this project. They thank members of the steering committee, who offered valuable feedback at various stages. (See http://www.eoloptionacttaskforce.org for more information about the steering committee meetings.) 


\section{Author Disclosure Statement}

The authors have no conflicts of interest to report.

\section{References}

1. Eggman S: Assembly bill No. 15: End of life. https:// leginfo.legislature.ca.gov/faces/billNavClient.xhtml?bill_id= 201520162AB15. (Last accessed February 25, 2019).

2. Clodfelter RP, Adashi EY: The liberty to die: California enacts physician aid-in-dying law. JAMA 2016;315:251252.

3. Gostin LO, Roberts AE: Physician-assisted dying: A turning point? JAMA 2016;315:249-250.

4. Mishra R: Implementing California's law on assisted dying. Hastings Cent Rep 2017;47:7-8.

5. Cain CL: Implementing aid in dying in California: Experiences from other states indicates the need for strong implementation guidance. Policy Brief UCLA Cent Health Policy Res 2016;PB2016-4:1-8.

6. Sung C: Deciding with dignity: The terminally ill patient's right to information about the California End of Life Option Act. Hastings Constit Law Q 2016;44:89-113.

7. Shaner DM: Ethical analysis for physicians considering the provision of life-ending medication in compliance with the California End of Life Option Act. Perm J 2016;20:116-121.

8. Kane CK: Updated Data on Physician Practice Arrangements: Physician Ownership Drops Below 50 Percent. Chicago, IL: American Medical Association, 2017.

9. Peled H, Bickel KE, Puchalski C: Enhancing informed consent for physician aid in dying: Potential role of handout on possible benefits of palliative care. J Oncol Pract 2017; 13:e838-e843.

10. Cain CL, Koenig BA, Starks H, et al.: Hospital responses to End of Life Option Act: Implementation of AID in Dying in California. JAMA Internal Med 2018;179:985-987.

11. American Hospital Association Forum: Fast Facts on US Hospitals. Chicago, IL: American Hospital Association, 2018.

12. Institutes of Medicine: Dying in America: Improving Quality and Honoring Individual Preferences Near the End of Life. National Academies Press, Washington, DC, 2015.

13. Brinkman-Stoppelenburg A, Rietjens JAC, van der Heide A: The effects of advance care planning on end-of-life care: A systematic review. Palliat Med 2014;28:1000-1025.

14. Office of Statewide Health Planning and Development: Hospital Annual Utilization Data. 2016. Dataset accessed August 2017.
15. Harrison $\mathrm{K}$, Bourne $\mathrm{M}$, Campbell $\mathrm{C}$, et al.: Neither hastening nor prolonging death: Hospice in a state with legalized physician-assisted death (FR460). J Pain Symptom Manag 53:376-377.

16. Campbell CS, Black MA: Dignity, death, and dilemmas: A study of Washington hospices and physician-assisted death. J Pain Symptom Manag 2014;47:137-153.

17. Dobscha SK, Heintz RT, Press N, Ganzini L: Oregon physicians' responses to requests for assisted suicide: A qualitative study. J Palliat Med 2004;7:451-461.

18. Ganzini L, Nelson HD, Schmidt TA, et al.: Physicians' experiences with the Oregon Death with Dignity Act. N Engl J Med 2000;342:557-563.

19. Lee MA, Nelson HD, Tilden VP, et al.: Legalizing assisted suicide-Views of physicians in Oregon. N Engl J Med 1996;334:310-315.

20. Harman SM, Magnus D: Early experience with the California End of Life Option Act: Balancing institutional participation and physician conscientious objection. JAMA Intern Med 2017;177:907-908.

21. Stata Statistical Software: Release 15 [computer program]. College Station, TX: StataCorp LLC, 2017.

22. Bradley EH, Curry LA, Devers KJ: Qualitative data analysis for health services research: Developing taxonomy, themes, and theory. Health Serv Res 2007;42:1758-1772.

23. CDPH: California End of Life Option Act 2017 Data Report. Sacramento, CA: California Department of Public Health, 2018.

24. Bryant T: Aid in Dying: The availability of ideal medications for use in the right to die jurisdictions in the United States. Quinnipiac Law Rev 2015;34:705.

25. Petrillo LA, Dzeng E, Smith AK: California's End of Life Option Act: Opportunities and challenges ahead. J Gen Intern Med 2016;31:828-829.

26. Ganzini L, Back AL: The challenge of new legislation on physician-assisted death. JAMA Intern Med 2016;176: $427-428$

Address correspondence to:

Cindy L. Cain, PhD

Department of Sociology

University of Alabama at Birmingham

1401 University Boulevard

Birmingham, AL 35294

E-mail: clcain@uab.edu 